\title{
Denosumab May Increase the Risk of Local Recurrence in Patients with Giant-Cell Tumor of Bone Treated with Curettage
}

\author{
Costantino Errani, MD, PhD, Shinji Tsukamoto, MD, PhD, Giulio Leone, MD, Alberto Righi, MD, PhD, \\ Manabu Akahane, MD, PhD, Yasuhito Tanaka, MD, PhD, and Davide Maria Donati, MD, $\mathrm{PhD}$ \\ Investigation performed at the Departments of Orthopaedic Oncology and Pathology, Rizzoli Institute, Bologna, Italy
}

\begin{abstract}
Background: Recent clinical studies have suggested that denosumab is associated with tumor response and reduced surgical morbidity in patients with giant-cell tumor of bone (GCTB). We therefore evaluated the recurrence-free survival rate of patients who had GCTB in an extremity and were treated with surgery and denosumab, to determine the influence of denosumab and clinical factors on the risk of local recurrence.

Methods: We retrospectively reviewed the medical records of 408 patients treated for GCTB in an extremity in a single institution from 1990 through 2013. Two hundred and forty-seven patients underwent curettage (intralesional surgery) with a high-speed burr, and 161 underwent resection. Phenol adjuvant was used in 221 of the 247 patients who had curettage. We also reviewed the medical records of 30 patients treated surgically ( 25 with curettage and 5 with resection) and with denosumab from 2010 through 2013 and compared their clinical results with 378 historical control subjects. The overall minimum duration of follow-up was 24 months.
\end{abstract}

Results: The local recurrence rates were $60 \%$ (15) of 25 patients treated with curettage and denosumab and $16 \%$ (36) of 222 patients treated with curettage alone. The joint preservation rates were $80 \%$ (20) of 25 patients treated with curettage and denosumab and 94\% (209) of 222 patients treated with curettage alone. Univariate and multivariable analyses showed that denosumab was the only independent factor associated with a poor prognosis when recurrence-free survival and joint preservation were considered. The overall median duration of follow-up was 85.6 months (interquartile range, 54.3 to 125.1 months). Viable tumor was present in all 30 specimens from patients treated with denosumab.

Conclusions: There was a higher rate of recurrence in the cohort exposed to denosumab. Because there were substantial differences in the cohorts and randomization was not applied, however, causation could not be evaluated.

Level of Evidence: Therapeutic Level III. See Instructions for Authors for a complete description of levels of evidence.

$\mathrm{G}$ iant-cell tumor of bone (GCTB), a rare primary benign bone tumor, accounts for approximately $5 \%$ of all primary bone tumors. ${ }^{1}$ Treatment of GCTB remains controversial $^{2}$. Surgical options include intralesional surgery (curettage) using a high-speed burr or resection. Curettage, which preserves adjacent joint function, is associated with a higher recurrence rate, whereas resection with wide margins minimizes tumor recurrence but is associated with worse functional results ${ }^{3}$. Clinical studies recently have suggested that denosumab-a monoclonal antibody that binds RANKL (receptor activation of nuclear factor-kappa $\beta$ ligand)—is associated with tumor re- sponse and reduced surgical morbidity in patients with $\mathrm{GCTB}^{47}$. Denosumab also has been reported to result in beneficial surgical downstaging ${ }^{6-8}$; however, the results were from patients who remained on denosumab or in whom it had been discontinued but who had been followed only a median of 13 months ${ }^{6,8}$.

We therefore evaluated the recurrence-free survival rate of patients with GCTB in an extremity who underwent both surgery and denosumab treatment of the tumor and who had a long follow-up. We determined the influence of several factors on the risk of recurrence after surgery, including denosumab administration, local tumor presentation, and demographic

Disclosure: There was no external funding for this study. The authors declare that they have no conflicts of interest. The Disclosure of Potential Conflicts of Interest forms are provided with the online version of the article (http://links. Iww.com/JBJS/E596). 
The Journal of Bone \& Joint Surgery $\cdot$ JBjS. org Volume 100-A · Number $6 \cdot$ March 21, 2018
Denosumab May Increase Risk of Local Recurrence in Patients with Giant-Cell Tumor of Bone characteristics. We hypothesized that denosumab contributes to a lower rate of local recurrence after surgery.

\section{Materials and Methods}

We retrospectively reviewed the medical records of W 412 patients diagnosed with histologically confirmed GCTB in an extremity from January 1990 to December 2013 and with a minimum follow-up of 24 months. A total of 247 patients underwent curettage, and 161 had resection. Four patients who required amputation were excluded from the study because they were at no risk of local recurrence.

The clinical characteristics of the 247 patients treated with curettage are summarized in Table I. The median age of the patients was 29.2 years (interquartile range [IQR], 23.0 to 38.5 years). We divided the patients into 2 groups according to the location of the tumor because it was reported that the distal radial site was associated with a higher local recurrence rate. Thus, 1 group comprised patients with GCTB in the distal end of the radius, and the other comprised patients with GCTB at other sites.

TABLE I Association of Denosumab Administration with Clinical Variables in the Patients Treated with Curettage

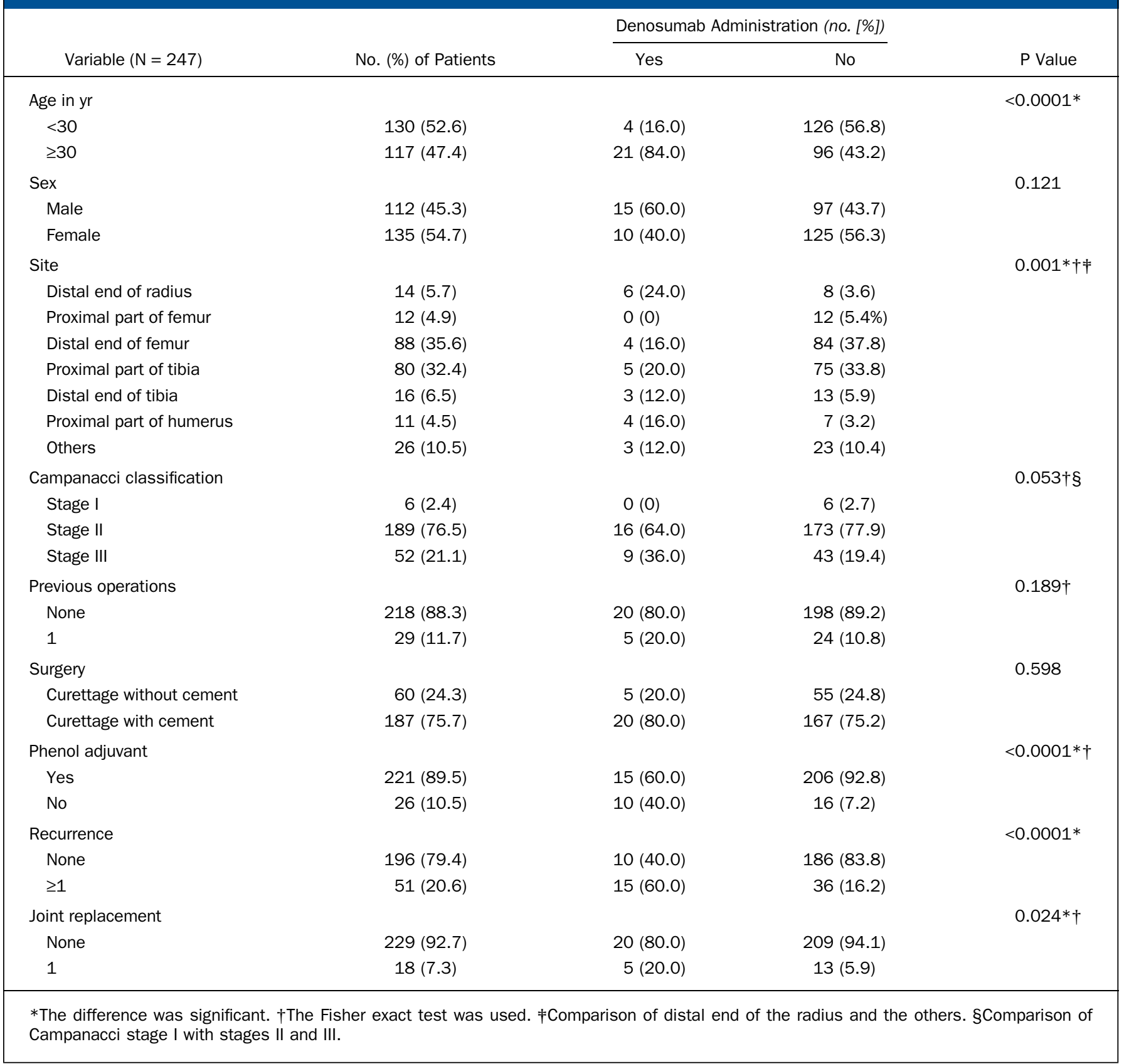


The Journal of Bone \& Joint Surgery $\cdot$ JBJS. Org Volume 100-A · Number $6 \cdot$ March 21,2018
Denosumab May Increase Risk of Local Recurrence in

Patients with Giant-Cell Tumor of Bone

\section{TABLE II Univariate Analysis of Recurrence-Free Survival in the Patients Treated with Curettage}

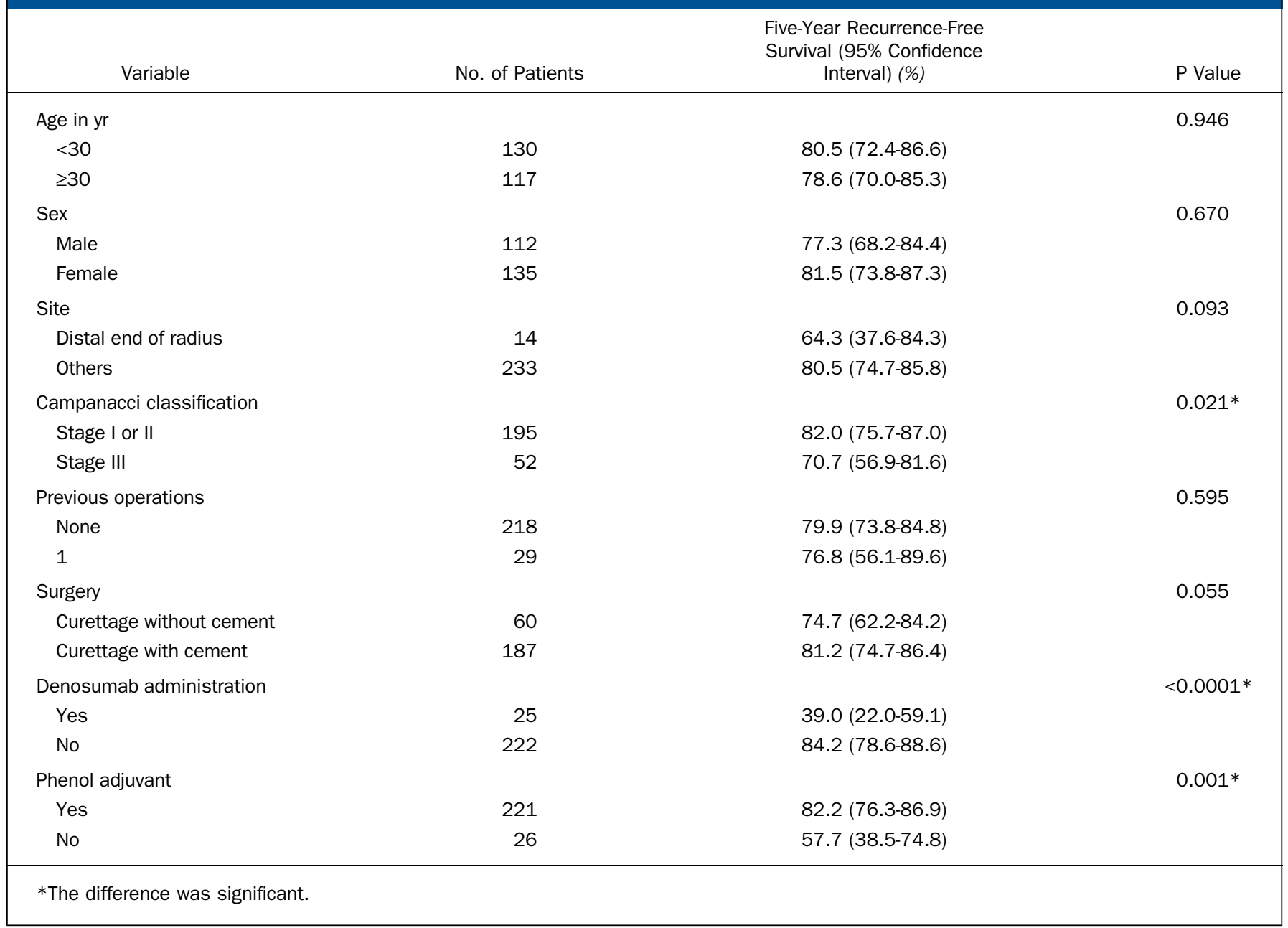

Previous clinical studies have suggested that denosumab was associated with tumor response and reduced surgical morbidity in patients with $\mathrm{GCTB}^{5}$. Therefore, we identified $30 \mathrm{pa}-$ tients ( 25 treated with curettage and 5 treated with resection) from an open-label, parallel group in a Phase-II trial (AMG20062004 [ClinicalTrials.gov identifier: NCT00680992]), conducted from 2010 to 2013, or who had received denosumab on an off-label basis, and included them in the study. Denosumab was used particularly in patients with GCTB in the distal end of the radius (for downstaging the tumor) because tumors at this site are aggressive and their resection is associated with worse functional results ${ }^{9}, 10$. Preoperatively, denosumab $(120 \mathrm{mg})$ was given subcutaneously once a week for 1 month and then once a month for 6 to 12 months. Postoperatively, it was given at the same dose once a month for 3 to 7 months ${ }^{11}$. The patients also took daily calcium $(2,500 \mathrm{mg})$ and vitamin D ( $\geq 400 \mathrm{IU})$ supplements.

After following the preoperative denosumab regimen, all patients had remaining tumor and therefore underwent surgery, usually 1 month after the final denosumab injection. To

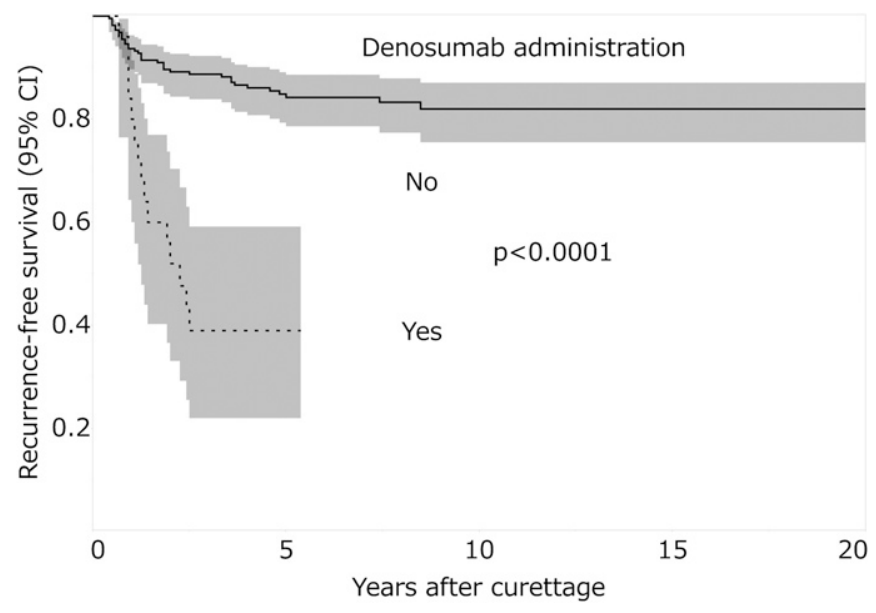

Fig. 1

Kaplan-Meier analysis of local recurrence-free survival in 247 patients with GCTB who were treated with curettage with or without denosumab administration. The shading surrounding the curves represents the $95 \%$ confidence interval $(\mathrm{Cl})$. 
The Journal of Bone \& Joint Surgery · Jbjs.org Volume 100-A · Number $6 \cdot$ March 21,2018

\begin{tabular}{|c|c|c|}
\hline Variable & $\begin{array}{c}\text { Hazard Ratio } \\
\text { (95\% Confidence } \\
\text { Interval) }\end{array}$ & P Value \\
\hline \multicolumn{3}{|c|}{ Campanacci classification } \\
\hline $\begin{array}{l}\text { Stage III versus } \\
\text { stage I or II }\end{array}$ & $1.73(0.95-3.15)$ & 0.075 \\
\hline \multicolumn{3}{|l|}{$\begin{array}{l}\text { Denosumab } \\
\text { administration }\end{array}$} \\
\hline Yes versus no & $4.78(2.45-9.35)$ & $<0.0001^{*}$ \\
\hline \multicolumn{3}{|l|}{ Phenol adjuvant } \\
\hline Yes versus no & $0.56(0.28-1.16)$ & 0.117 \\
\hline
\end{tabular}

assess the effect of denosumab, radiographic images made just before denosumab administration were compared with those made just before surgery to determine the best response as
Denosumab May Increase Risk of Local Recurrence in

Patients with Giant-Cell Tumor of Bone measured with modified inverse Choi (density/size) crite$\mathrm{ria}^{6,7,12}$. Adverse events and laboratory abnormalities were assessed using Common Terminology Criteria for Adverse Events (CTCAE; version 4.0 $)^{13}$.

The patients were managed surgically with curettage or with resection, which was indicated for large tumors with softtissue extension, pathological fractures with joint invasion or an unstable fracture pattern, multiple recurrences, or involvement of expendable bones (head of the fibula or distal end of the ulna) ${ }^{10}$. Curettage was performed through a large cortical bone window using curets of different sizes that enabled removal of all visible tumor. The cavity was then cleaned with a high-speed burr and was washed in an attempt to remove all pathological tissue ${ }^{10}$. In 221 of the 247 patients who had curettage, phenol was applied to the border of the cavity with cotton-tipped applicators and then was neutralized with alcohol. The tumor cavity was left alone or packed with bone allografts, cement, or cement with bone allografts. Cement and bone allograft reconstruction was performed in 2 steps. First, the cavity was filled with cement after bone chip allografts were placed in a subchondral area to protect the articular surface

\section{TABLE IV Univariate Analysis of Joint Preservation Survival in the Patients Treated with Curettage}

\begin{tabular}{|c|c|c|c|}
\hline Variable & No. of Patients & $\begin{array}{l}\text { Five-Year Joint Preservation } \\
\text { (95\% Confidence Interval) (\%) }\end{array}$ & P Value \\
\hline Age in yr & & & 0.965 \\
\hline$\geq 30$ & 117 & 93.7 (87.3-97.0) & \\
\hline Sex & & & 0.719 \\
\hline Site & & & 0.935 \\
\hline Distal end of radius & 14 & $92.9(63.0-99.0)$ & \\
\hline Others & 233 & $93.4(89.3-96.0)$ & \\
\hline Campanacci classification & & & 0.739 \\
\hline Stage I or II & 195 & $93.7(89.2-96.4)$ & \\
\hline 1 & 29 & $93.1(76.2-98.3)$ & \\
\hline Surgery & & & 0.960 \\
\hline Curettage without cement & 60 & $93.3(83.4-97.5)$ & \\
\hline Curettage with cement & 187 & $93.4(88.7-96.2)$ & \\
\hline Denosumab administration & & & $0.002 *$ \\
\hline Yes & 25 & $79.8(59.7-91.3)$ & \\
\hline No & 222 & $94.9(91.1-97.2)$ & \\
\hline Phenol adjuvant & & & 0.057 \\
\hline Yes & 221 & $94.4(90.4-96.8)$ & \\
\hline No & 26 & $84.6(65.5-94.1)$ & \\
\hline
\end{tabular}


The Journal of Bone \& Joint Surgery $\cdot$ Jbjs.org Volume 100-A · Number $6 \cdot$ March 21, 2018

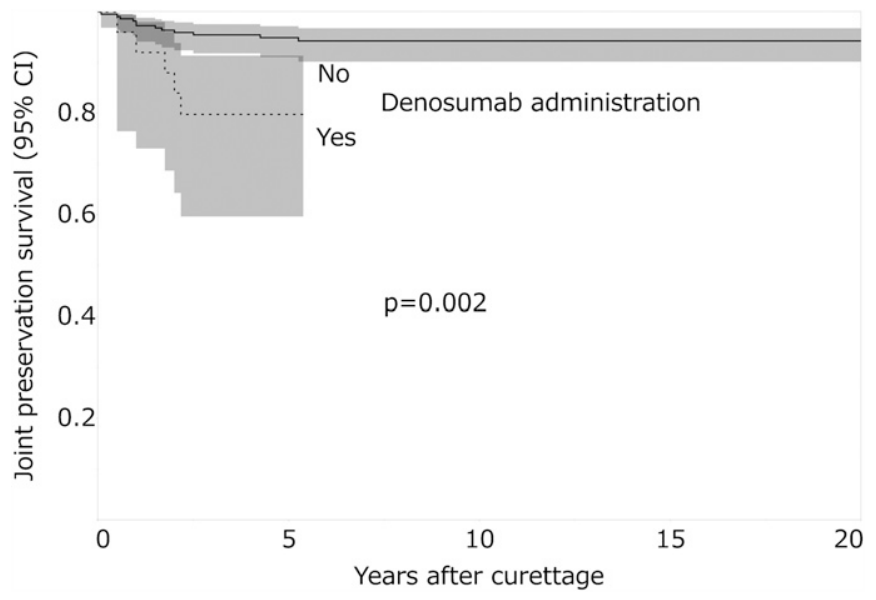

Fig. 2

Kaplan-Meier analysis of joint preservation survival in 247 patients with GCTB who underwent curettage with or without denosumab administration. The shading surrounding the curves represents the $95 \%$ confidence interval $(\mathrm{Cl})$.

from the thermal effect of cement. Second, the cavity was filled with cement and cortical bone allografts to support the articular surface mechanically ${ }^{10,14}$. Prophylactic surgical stabilization with internal fixation was also performed in 5 patients at high risk of a pathological fracture.

Patients who had undergone resection had reconstruction using a modular prosthesis, massive bone allografts, or allograft composite prostheses. The only exceptions were patients whose tumors were in the proximal part of the fibula or the distal end of the ulna. They did not undergo reconstruction.

Finally, the results of the 30 tumor samples from diagnostic biopsies and curettage or resection procedures done after denosumab administration were analyzed and compared histologically.

Routine follow-up included a clinical examination and conventional radiography. The Musculoskeletal Tumor Society (MSTS) score, developed by Enneking et al., was used to assess functional results ${ }^{15}$.

Recurrence-free survival was defined as the interval between the first surgery and the manifestation of local recurrence discovered by radiographic imaging during follow-up. Joint preservation survival was defined as the interval between the first curettage and joint replacement for the local recurrence.

The chi-square test or Fisher exact test was used to evaluate the association between 2 variables, as appropriate. Recurrence-free survival and joint preservation were estimated using the Kaplan-Meier method. The log-rank test was used to evaluate differences between the survival curves. Cox proportional hazards regression analysis was conducted to estimate the hazard ratios for risk factors for recurrence and joint replacement. The difference between 2 independent samples was statistically analyzed using the Mann-Whitney $U$ test for nonparametric analyses. Significance was defined as $p<0.05$. All analyses were performed with IBM SPSS (version 21.0; IBM) and JMP 11 (SAS Institute).
Denosumab May Increase Risk of Local Recurrence in

Patients with Giant-Cell Tumor of Bone
The independent ethics committee of our institution approved the study, which was registered with ClinicalTrials. gov (identifier NCT02996734).

\section{Results}

Univariate analysis revealed that Campanacci stage III $(\mathrm{p}=0.021)$ and denosumab administration $(\mathrm{p}<$ 0.0001 ) had a significant association with unfavorable recurrence-free survival in the 247 patients treated with curettage (Table II, Fig. 1) ${ }^{16}$. Phenol adjuvant, in contrast, showed a significant association with favorable recurrencefree survival $(p=0.001)$ (Table II). A multivariable analysis that was conducted with clinical variables related to unfavorable recurrence-free survival revealed that denosumab administration was the only independent prognostic factor for poor recurrence-free survival ( $p<0.0001)$ (Table III). Univariate analysis revealed that denosumab administration showed a significant association with unfavorable joint preservation in the 247 patients treated with curettage $(\mathrm{p}=$ 0.002) (Table IV, Fig. 2). A multivariable analysis was conducted only with clinical variables that were related to local recurrence in previous reports. The multivariable analysis revealed that denosumab administration was the only independent prognostic factor associated with poor joint preservation $(\mathrm{p}=0.018)($ Table $\mathrm{V})$.

Wide resection was associated with a significantly $(\mathrm{p}=$ 0.049 ) lower recurrence rate than intralesional surgery (curettage): $13 \%$ (21 of 161 patients) compared with $21 \%$ (51 of 247 patients), respectively. Lung metastases occurred in $4.9 \%$ (20) of all 408 patients. The median follow-up was 85.6 months (IQR, 54.3 to 125.1 months). Three patients were followed up for the minimum of 24 months.

\begin{tabular}{|c|c|c|}
\hline Variable & $\begin{array}{c}\text { Hazard Ratio } \\
\text { (95\% Confidence } \\
\text { Interval) }\end{array}$ & $P$ Value \\
\hline \multicolumn{3}{|l|}{ Site } \\
\hline $\begin{array}{l}\text { Distal end of radius } \\
\text { versus other sites }\end{array}$ & $0.43(0.05-4.09)$ & 0.466 \\
\hline \multicolumn{3}{|c|}{ Campanacci classification } \\
\hline $\begin{array}{l}\text { Stage III versus } \\
\text { stage I or II }\end{array}$ & $1.13(0.34-3.68)$ & 0.846 \\
\hline \multicolumn{3}{|l|}{ Surgery } \\
\hline $\begin{array}{l}\text { With cement versus } \\
\text { without cement }\end{array}$ & $0.94(0.30-2.94)$ & 0.919 \\
\hline \multicolumn{3}{|c|}{ Denosumab administration } \\
\hline Yes versus no & $4.12(1.27-13.35)$ & $0.018 *$ \\
\hline \multicolumn{3}{|l|}{ Phenol adjuvant } \\
\hline Yes versus no & $0.50(0.15-1.72)$ & 0.272 \\
\hline
\end{tabular}


The Journal of Bone \& Joint Surgery - Jbjs.org Volume 100-A · Number 6 - March 21, 2018
Denosumab May Increase Risk of Local Recurrence in

Patients with Giant-Cell Tumor of Bone

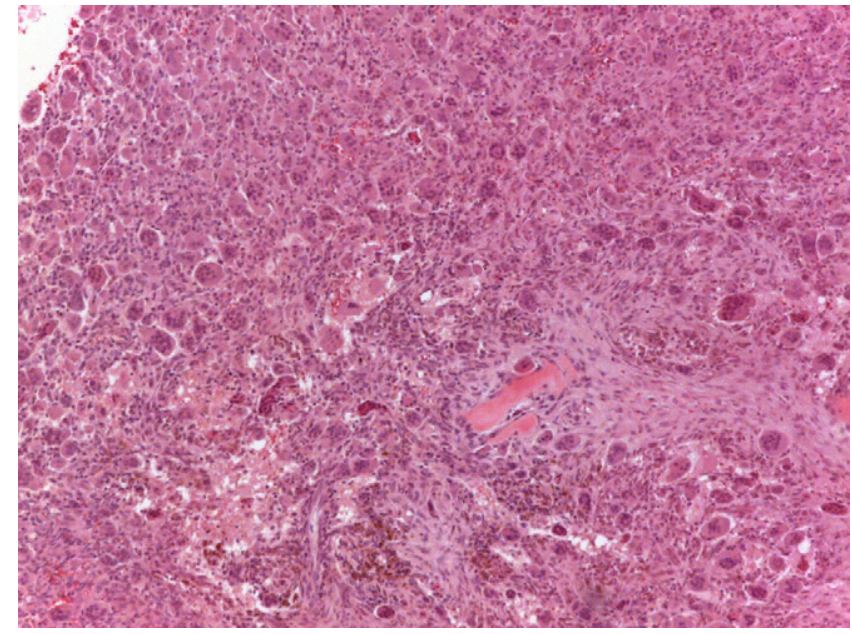

Fig. 3-A

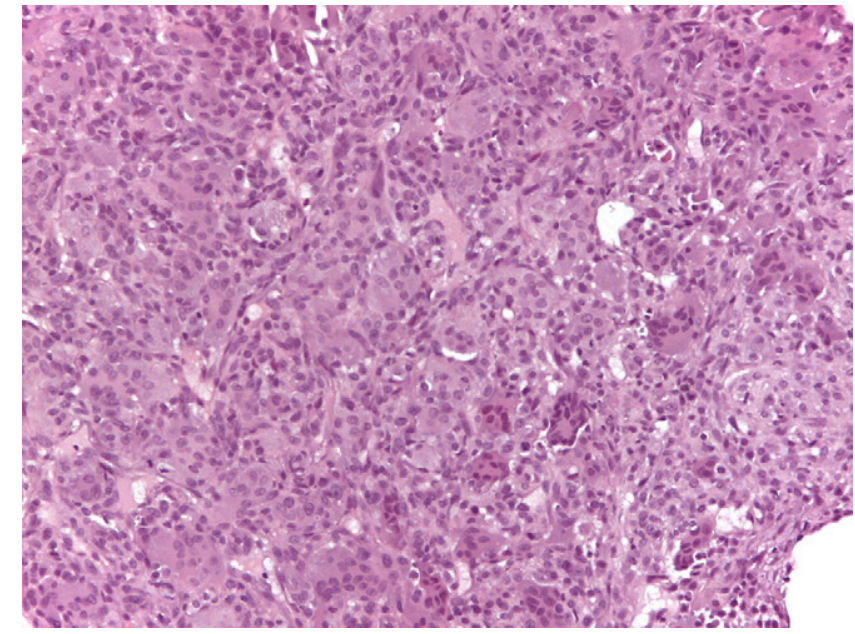

Fig. 3-B

Figs. 3-A and 3-B Tumor biopsy specimen after hematoxylin and eosin staining reveals that the GCTB is composed of an admixture of neoplastic mononuclear cells and numerous, evenly distributed, osteoclast-type giant cells associated with hemosiderin deposits and focal reactive bone formation.

Fig. 3-A Magnification, $\times 100$. Fig. 3-B Magnification, $\times 200$.

Denosumab was more frequently administered in patients who were $\geq 30$ years old $(\mathrm{p}<0.0001)$ and who had GCTB in the distal end of the radius ( $\mathrm{p}=0.001)$ (Table I). Phenol was used less frequently in patients who received denosumab than in those who did not receive denosumab $(\mathrm{p}<0.0001)$ (Table I). Phenol was used less frequently at the distal radial site than at other sites: $64.3 \%$ (9 of 14 patients) compared with $91.0 \%$ (212 of 233 patients) $(\mathrm{p}=0.009)$, respectively. There was a significant association between denosumab administration and both local recurrence $(p<0.0001)$ and joint replacement $(p=0.024)$ (Table I). In 25 patients treated with curettage and denosumab, the use of phenol adjuvant was not associated with age, sex, tumor site, Campanacci stage, previous surgery, or the use of cement. For the 25 patients treated with curettage and denosumab, the median duration of follow-up was 42.1 months (IQR, 37.4 to 50.8 months). Ten patients remained disease-free, and 15 had no evidence of disease after treatment of a local recurrence. The local recurrence rate was $60 \%$ (15 patients), and the median interval between the first surgical treatment and local recurrence was 15.0 months (IQR, 11.0 to 24.0 months). The joint preservation rate was $80 \%$ (20 patients), and the median interval between the first surgical treatment and joint replacement was 21.0 months (IQR, 9.0 to 25.0 months).

For the 222 patients who underwent curettage with a high-speed burr without denosumab, the median follow-up

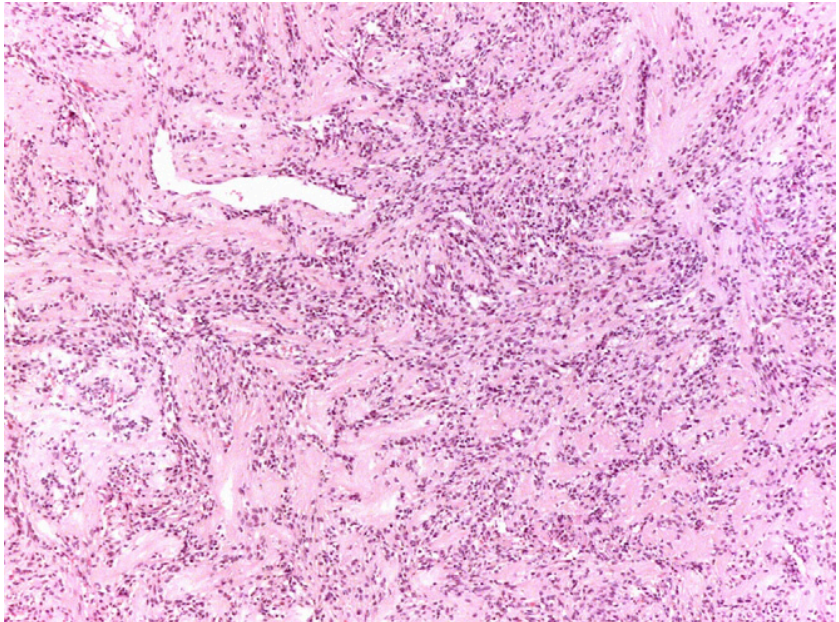

Fig. 4 -A

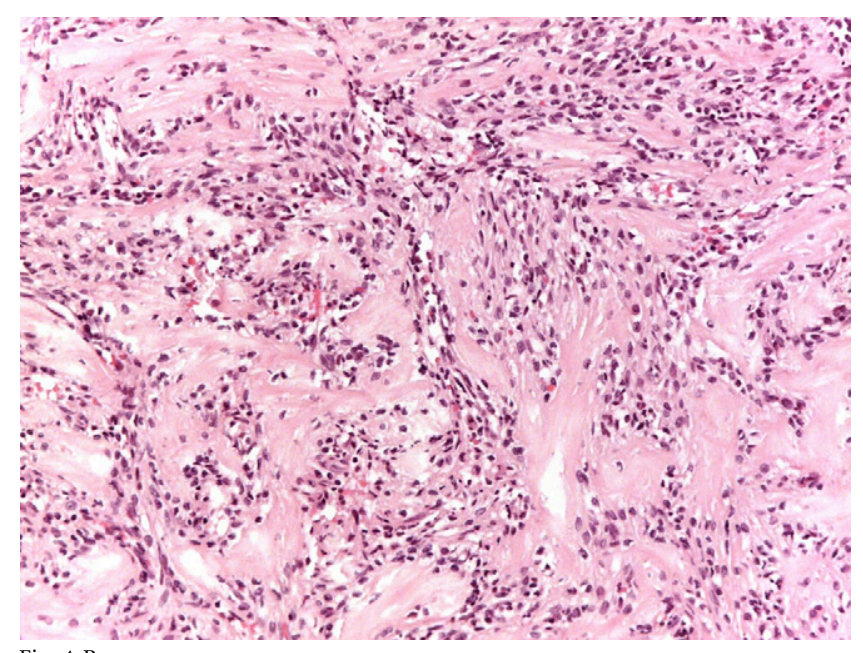

Fig. $4-\mathrm{B}$

Figs. 4-A and 4-B Hematoxylin and eosin staining of GCTB after denosumab treatment reveals that the residual tumor is composed of bland-appearing spindle cells organized in short fascicles with a storiform pattern, associated with collagen matrix production. This matrix appears either as thin bands or as thicker connected trabecular structures with a honeycomb appearance Fig. 4-A Magnification, $\times 100$. Fig. 4-B Magnification, $\times 200$. 
The Journal of Bone \& Joint Surgery · Jbjs.org Volume 100-A · Number 6 - March 21, 2018
Denosumab May Increase Risk of Local Recurrence in Patients with Giant-Cell Tumor of Bone was 88.4 months (IQR, 57.1 to 123.9 months). With respect to the oncologic results, 182 patients remained disease-free, and 36 had no evidence of disease after treatment of a local recurrence. One patient had no evidence of disease after treatment of lung metastasis, and 2 patients were alive with lung metastases. One patient died of another disease. The local recurrence rate was $16 \%$ (36 patients), and the median interval between the first surgical treatment and local recurrence was 15.0 months (IQR, 9.0 to 43.0 months). The joint preservation rate was $94 \%$ (209 patients), and the median interval between the first surgical treatment and joint replacement was 42.0 months (IQR, 7.0 to 46.0 months). Lung metastases occurred in 3 patients $(1.4 \%)$. The median interval between the primary disease diagnosis and lung metastasis was 49.6 months (IQR, 36.5 to 52.4 months).

The median MSTS score was 96.7 (IQR, 85 to 100) for the 25 patients receiving denosumab and 96.7 (IQR, 90 to 100) for the 222 patients who did not receive denosumab. Hence, there was no significant difference among the 247 patients who had curettage $(\mathrm{p}=0.372)$. For the 161 patients who had resection, univariate analysis revealed that denosumab administration was not associated with recurrence-free survival ( $\mathrm{p}=$ 0.425).

With regard to tumor response and adverse events among the 30 patients treated with denosumab, 6 (24\%) of 25 patients managed with curettage had stable disease and 19 $(76 \%)$ had a partial response. Of the 5 patients who underwent resection, 2 had stable disease and 3 had a partial response. During denosumab treatment, 2 patients (7\%) reported gradeIII adverse events and were unable to continue denosumab therapy after surgery. One patient had a periapical abscess, and the other had grade-III periodontal disease. None of the other patients experienced adverse events during denosumab therapy and so completed the regimen.

Histopathological examination of the diagnostic tumor biopsy specimens confirmed morphology typical of GCTB in all cases (Figs. 3-A and 3-B): an admixture of neoplastic mononuclear cells and numerous, evenly distributed osteoclast-type giant cells associated with hemosiderin deposits and focal reactive bone formation on hematoxylin-eosin staining. Following denosumab treatment, all samples showed pronounced changes and viable tumor (Figs. 4-A and 4-B): osteoclast-like giant cells had disappeared. Cellular areas characterized by sheets of round-ovoid tumor cells or spindle cells had formed in a storiform pattern with little or no extracellular matrix. Other areas were characterized by an abundant fibrillary extracellular matrix organized in trabecular structures or with increased honeycomb-pattern bone. These histological patterns were not haphazardly distributed in resected specimens but tended toward a "zonal" distribution, with more cellular areas in the central portion of the tumor and matrix-rich areas in the periphery. At the periphery of the tumor, the osteoid-like matrix seemed to merge with host bone.

\footnotetext{
Discussion

7 his study of GCTB in an extremity showed that denosumab administration apparently increased the rate of local re-
}

currence and the need for joint replacement after curettage. Similar to findings in previous studies ${ }^{1,10,16-19}$, there was a significantly lower risk of recurrence after wide resection than after curettage. Some authors have recommended local adjuvants combined with curettage to reduce the risk of recurrence $^{18-20}$, whereas others consider it unnecessary ${ }^{21,22}$. Prosser et $\mathrm{al}^{21}$ reported a low overall recurrence rate (19\%) for 137 patients who underwent curettage alone. Turcotte et al. ${ }^{22}$ reported that the nature of the cement filling had no significant impact on the risk of recurrence in 148 patients treated with curettage, including 64 who had cement filling. In our study, the use of phenol adjuvant (but not cement) significantly decreased the risk of local recurrence.

The U.S. Food and Drug Administration approved the use of denosumab for treating adults and skeletally mature adolescents with unresectable GCTB or when resection is likely to result in severe morbidity ${ }^{6}$. Thomas et al. ${ }^{5}$ reported an openlabel Phase-II study in which they showed clinical benefit when treating GCTB with denosumab. In $86 \%$ (30) of 35 patients, there was a tumor response to denosumab, as assessed by histological and radiographic evaluations. Only a small number of these patients, however, underwent intralesional surgery after denosumab. Thus, it remains unknown whether the local recurrence rate was affected by denosumab in that study.

Chawla et al. ${ }^{6}$ confirmed the efficacy (which included reduction in the need for morbid surgery) and the safety of denosumab in 282 patients affected by GCTB. As in the investigation by Thomas et al. ${ }^{5}$, they studied patients still on denosumab treatment and 25 patients who underwent surgery after denosumab treatment with a median follow-up of only 9.2 months, which is inadequate for definitive conclusions.

Another open-label Phase-II study evaluated reduced surgical invasiveness after denosumab treatment in 222 patients with resectable GCTB that was able to be evaluated for surgical downstaging ${ }^{8}$. Of the 115 patients who had surgery, 17 (15\%) experienced local recurrence during a median follow-up of 13.0 months (IQR, 8.5 to 17.9 months). The median time to recurrence was 13.6 months (IQR, 10.5 to 15.7 months) postoperatively. For the 99 patients who underwent surgery but had no local recurrence, the median postoperative follow-up was 12.9 months (IQR, 7.8 to 18.0 months). The authors warned that these results must be interpreted with caution because of the short follow-up time.

Traub et al. ${ }^{23}$, in a prospective nonrandomized study of patients with GCTB who received denosumab for 6 to 11 months preoperatively, reported that all patients underwent intralesional surgery, with local recurrence in 3 of the 18 patients at 10, 12, and 25 months postoperatively; the median follow-up was 30 months (range, 20 to 45 months). The local control rate was comparable with those in other studies in which denosumab was not used before curettage ${ }^{10,21,22}$. Hence, these data do not indicate that denosumab improved local control of GCTB. The authors reported that the new osseous tumor matrix and the thickened cortical bone that developed following denosumab treatment raise a new surgical challenge by not allowing the surgeon to delineate the true extent of the 
The Journal of Bone \& Joint Surgery · Jbjs.org Volume 100-A - Number 6 - March 21, 2018
Denosumab May Increase Risk of Local Recurrence in

Patients with Giant-Cell Tumor of Bone tumor. They theorized that tumor cells can "hide" within the thickened cortex and subchondral bone, which could increase the risk of local recurrence.

Our data showed an unacceptably large increase in local recurrence in patients treated with denosumab and without phenol. Further investigation of the role of denosumab and phenol as adjuvant treatments is warranted. In the present report, we describe the results for 25 patients with GCTB who underwent curettage following denosumab with a median follow-up of 42.1 months. The local recurrence rate was $60 \%$ (15 patients). Follow-up for these patients was longer than in previous studies, which may explain the higher local recurrence rate.

A recent in vitro study that assessed the viability and osteoclastogenic capabilities of neoplastic stromal cells of $\mathrm{GCTB}^{24}$ showed that cell proliferation is only diminished by denosumab. Thus, the cells continue to proliferate in vitro, albeit at a slower rate. These data suggested that denosumab actively inhibits osteoclastogenesis biologically. Although the stromal cells were quiescent during drug exposure, the neoplastic cells again proliferated once the microenvironment was free of denosumab ${ }^{24}$. We also observed residual neoplastic stromal cells following denosumab administration.

With the very small numbers available, we were not able to show an effect of denosumab administration on local recurrence in patients with resected GCTB. Several authors reported that denosumab seems to improve subchondral and cortical bone by reconstituting a peripheral rim, allowing easier resection $^{4,23,25-27}$.

An objective tumor response (defined by modified inverse Choi criteria as a partial or complete response) was noted in $22(73 \%)$ of 30 patients. Chawla et al. ${ }^{6}$ reported that $76 \%$ of 176 patients had an objective tumor response by the same criteria. Ueda et al. ${ }^{7}$ reported that $71 \%$ of 17 patients showed an objective tumor response. Objective tumor responses in our study were similar to those described in the latter 2 studies.

The present study has several limitations. First, it is retrospective, and the patients given denosumab treatment were compared with 378 historical control subjects, including patients treated by different surgeons over a 24 -year period and with different techniques. Second, the patients treated with curettage and denosumab differed considerably from those who underwent curettage alone. The group treated with denosumab were older, had more tumors in the distal end of the radius (which are associated with a higher rate of local recurrence), and had more Campanacci stage-III tumors. Phenol was used less frequently in the denosumab group. Even though multivariable analysis was used to correct the influence of confounding factors, it might not have been able to correct the influence of the major differences in the 2 groups, which is a limitation. Third, although the total sample size is relatively large, the number of patients in the denosumab group and the number of joint replacements in the curettage group are relatively small. Finally, we enrolled only patients treated at our institution.

There was a higher rate of recurrence in the cohort exposed to denosumab. Because there were substantial differences in the cohorts and randomization was not applied, however, causation could not be evaluated.

The ability to perform curettage correctly after denosumab treatment is a concern because the rim of new bone may contain tumor cells that could reactivate once denosumab treatment is completed ${ }^{4}$. We strongly recommend collaborative studies involving clinical trials and rigorous data collection to identify the optimum indications for using denosumab to treat GCTB of the extremities.

Note: The authors thank all of their patients and their families.

Costantino Errani, $\mathrm{MD}, \mathrm{PhD}^{1}$

Shinji Tsukamoto, $\mathrm{MD}, \mathrm{PhD}^{1,2}$

Giulio Leone, $\mathrm{MD}^{3}$

Alberto Righi, $\mathrm{MD}, \mathrm{PhD}^{1}$

Manabu Akahane, $\mathrm{MD}, \mathrm{PhD}^{2}$

Yasuhito Tanaka, MD, $\mathrm{PhD}^{2}$

Davide Maria Donati, $\mathrm{MD}, \mathrm{PhD}^{1}$

${ }^{1}$ Departments of Orthopaedic Oncology (C.E., S.T., and D.M.D.) and Pathology (A.R.), Rizzoli Institute, Bologna, Italy

${ }^{2}$ Departments of Orthopaedic Surgery (S.T. and Y.T.) and Public Health, Health Management, and Policy (M.A.), Nara Medical University, Nara, Japan

${ }^{3}$ Department of Orthopaedic Surgery, San Gerardo Hospital, Monza, Italy E-mail address for C. Errani: costantino.errani@ior.it

ORCID iD for C. Errani: 0000-0002-4504-2867

\section{References}

1. Klenke FM, Wenger DE, Inwards CY, Rose PS, Sim FH. Giant cell tumor of bone: risk factors for recurrence. Clin Orthop Relat Res. 2011 Feb;469(2):591-9. Epub 2010 Aug 13.

2. Wijsbek AE, Vazquez-Garcia BL, Grimer RJ, Carter SR, Abudu AA, Tillman RM, Jeys L. Giant cell tumour of the proximal femur: is joint-sparing management ever successful? Bone Joint J. 2014 Jan;96-B(1):127-31.

3. van der Heijden L, Dijkstra PD, van de Sande MA, Kroep JR, Nout RA, van Rijswijk CS, Bovée JV, Hogendoorn PC, Gelderblom H. The clinical approach toward giant cell tumor of bone. Oncologist. 2014 May;19(5):550-61. Epub 2014 Apr 9.

4. Gaston CL, Grimer RJ, Parry M, Stacchiotti S, Dei Tos AP, Gelderblom H, Ferrari S, Baldi GG, Jones RL, Chawla S, Casali P, LeCesne A, Blay JY, Dijkstra SP, Thomas DM, Rutkowski P. Current status and unanswered questions on the use of denosumab in giant cell tumor of bone. Clin Sarcoma Res. 2016 Sep 14;6 (1):15.

5. Thomas $D$, Carriere $P$, Jacobs $I$. Safety of denosumab in giant-cell tumour of bone. Lancet Oncol. 2010 Sep;11(9):815.

6. Chawla S, Henshaw R, Seeger L, Choy E, Blay JY, Ferrari S, Kroep J, Grimer R, Reichardt P, Rutkowski P, Schuetze S, Skubitz K, Staddon A, Thomas D, Qian Y Jacobs I. Safety and efficacy of denosumab for adults and skeletally mature adolescents with giant cell tumour of bone: interim analysis of an open-label, parallel-group, phase 2 study. Lancet Oncol. 2013 Aug;14(9):901-8. Epub 2013 Jul 16.

7. Ueda T, Morioka H, Nishida Y, Kakunaga S, Tsuchiya H, Matsumoto Y, Asami Y, Inoue $\mathrm{T}$, Yoneda $\mathrm{T}$. Objective tumor response to denosumab in patients with giant 
The Journal of Bone \& Joint Surgery $\cdot$ JBJS. Org Volume 100-A • Number 6 - March 21, 2018
Denosumab May Increase Risk of Local Recurrence in

Patients With Giant-Cell Tumor of Bone cell tumor of bone: a multicenter phase II trial. Ann Oncol. 2015 Oct;26(10):2149 54. Epub 2015 Jul 23.

8. Rutkowski P, Ferrari S, Grimer RJ, Stalley PD, Dijkstra SP, Pienkowski A, Vaz G, Wunder JS, Seeger LL, Feng A, Roberts ZJ, Bach BA. Surgical downstaging in an open-label phase II trial of denosumab in patients with giant cell tumor of bone. Ann Surg Oncol. 2015 Sep;22(9):2860-8. Epub 2015 Jun 2.

9. O'Donnell RJ, Springfield DS, Motwani HK, Ready JE, Gebhardt MC, Mankin HJ. Recurrence of giant-cell tumors of the long bones after curettage and packing with cement. J Bone Joint Surg Am. 1994 Dec;76(12):1827-33.

10. Errani C, Ruggieri P, Asenzio MA, Toscano A, Colangeli S, Rimondi E, Rossi G, Longhi A, Mercuri M. Giant cell tumor of the extremity: a review of 349 cases from a single institution. Cancer Treat Rev. 2010 Feb;36(1):1-7. Epub 2009 Oct 30.

11. Palmerini E, Chawla NS, Ferrari S, Sudan M, Picci P, Marchesi E, Leopardi MP, Syed I, Sankhala KK, Parthasarathy P, Mendanha WE, Pierini M, Paioli A, Chawla SP. Denosumab in advanced/unresectable giant-cell tumour of bone (GCTB): for how long? Eur J Cancer. 2017 May;76:118-24. Epub 2017 Mar 17.

12. Choi H, Charnsangavej C, Faria SC, Macapinlac HA, Burgess MA, Patel SR, Chen LL, Podoloff DA, Benjamin RS. Correlation of computed tomography and positron emission tomography in patients with metastatic gastrointestinal stromal tumor treated at a single institution with imatinib mesylate: proposal of new computed tomography response criteria. J Clin Oncol. 2007 May 1;25(13):1753-9.

13. U.S. Department of Health and Human Services, National Institutes of Health, National Cancer Institute. Common Terminology Criteria for Adverse Events (CTCAE) version 4.0. U.S. 2009 May 28. https://www.acrin.org/portals/0/administration/ regulatory/CTCAE_4.02_2009-09-15_quickreference_5x7.pdf. Accessed 2017 Oct 6. 14. van der Heijden L, van der Geest IC, Schreuder HW, van de Sande MA, Dijkstra PD. Liquid nitrogen or phenolization for giant cell tumor of bone?: a comparative cohort study of various standard treatments at two tertiary referral centers. J Bone Joint Surg Am. 2014 Mar 5;96(5):e35.

15. Enneking WF, Dunham W, Gebhardt MC, Malawar M, Pritchard DJ. A system for the functional evaluation of reconstructive procedures after surgical treatment of tumors of the musculoskeletal system. Clin Orthop Relat Res. 1993 Jan;286:241-6.

16. Campanacci M, Baldini N, Boriani S, Sudanese A. Giant-cell tumor of bone. J Bone Joint Surg Am. 1987 Jan;69(1):106-14.

17. Becker WT, Dohle J, Bernd L, Braun A, Cserhati M, Enderle A, Hovy L, Matejovsky Z, Szendroi M, Trieb K, Tunn PU; Arbeitsgemeinschaft Knochentumoren. Local recurrence of giant cell tumor of bone after intralesional treatment with and without adjuvant therapy. J Bone Joint Surg Am. 2008 May;90(5):1060-7.

18. Balke M, Schremper L, Gebert $C$, Ahrens H, Streitbuerger A, Koehler G, Hardes J, Gosheger G. Giant cell tumor of bone: treatment and outcome of 214 cases. J Cancer Res Clin Oncol. 2008 Sep;134(9):969-78. Epub 2008 Mar 6.

19. Kivioja AH, Blomqvist C, Hietaniemi K, Trovik C, Walloe A, Bauer HC, Jorgensen $\mathrm{PH}$, Bergh P, Follerås $\mathrm{G}$. Cement is recommended in intralesional surgery of giant cell tumors: a Scandinavian Sarcoma Group study of 294 patients followed for a median time of 5 years. Acta Orthop. 2008 Feb;79(1):86-93.

20. Lackman RD, Crawford EA, King JJ, Ogilvie CM. Conservative treatment of Campanacci grade III proximal humerus giant cell tumors. Clin Orthop Relat Res. 2009 May;467(5):1355-9. Epub 2008 Nov 6.

21. Prosser GH, Baloch KG, Tillman RM, Carter SR, Grimer RJ. Does curettage without adjuvant therapy provide low recurrence rates in giant-cell tumors of bone? Clin Orthop Relat Res. 2005 Jun;435:211-8.

22. Turcotte RE, Wunder JS, Isler MH, Bell RS, Schachar N, Masri BA, Moreau G, Davis AM; Canadian Sarcoma Group. Giant cell tumor of long bone: a Canadian Sarcoma Group study. Clin Orthop Relat Res. 2002 Apr;397:248-58.

23. Traub F, Singh J, Dickson BC, Leung S, Mohankumar R, Blackstein ME, Razak AR, Griffin AM, Ferguson PC, Wunder JS. Efficacy of denosumab in joint preservation for patients with giant cell tumour of the bone. Eur J Cancer. 2016 May;59:1-12. Epub 2016 Mar 15

24. Mak IW, Evaniew N, Popovic S, Tozer R, Ghert M. A translational study of the neoplastic cells of giant cell tumor of bone following neoadjuvant denosumab. J Bone Joint Surg Am. 2014 Aug 6;96(15):e127.

25. Müller DA, Beltrami G, Scoccianti G, Campanacci DA, Franchi A, Capanna R. Risks and benefits of combining denosumab and surgery in giant cell tumor of bone-a case series. World J Surg Oncol. 2016 Nov 4;14(1):281

26. Goldschlager T, Dea N, Boyd M, Reynolds J, Patel S, Rhines LD, Mendel E, Pacheco M, Ramos E, Mattei TA, Fisher CG. Giant cell tumors of the spine: has denosumab changed the treatment paradigm? J Neurosurg Spine. 2015 May;22 (5):526-33. Epub 2015 Feb 20

27. de Carvalho Cavalcante RA, Silva Marques RA, dos Santos VG, Sabino E, Fraga AC Jr, Zaccariotti VA, Arruda JB, Fernandes YB. Spondylectomy for giant cell tumor after denosumab therapy. Spine (Phila Pa 1976). 2016 Feb;41(3): E178-82. 